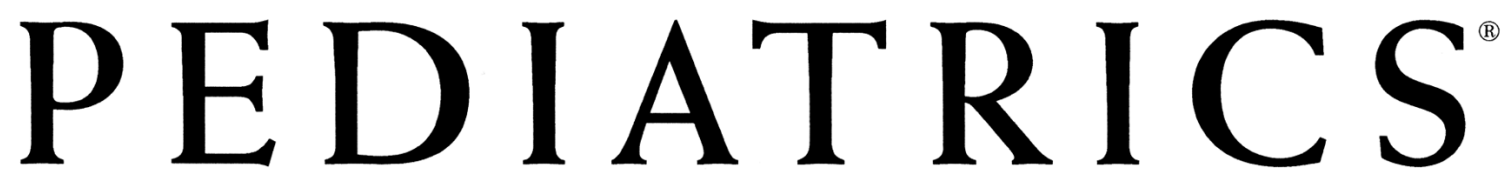

OFFICIAL JOURNAL OF THE AMERICAN ACADEMY OF PEDIATRICS

\title{
Psychiatric Morbidity in Children With Medically Unexplained Chronic Pain: Diagnosis From the Pediatrician's Perspective
}

Antoinette Y. Konijnenberg, Elisabeth R. de Graeff-Meeder, Joost van der Hoeven, Jan L. L. Kimpen, Jan K. Buitelaar and Cuno S.P.M. Uiterwaal Pediatrics 2006;117;889

DOI: $10.1542 /$ peds.2005-0109

The online version of this article, along with updated information and services, is located on the World Wide Web at: http://pediatrics.aappublications.org/content/117/3/889.full.html

PEDIATRICS is the official journal of the American Academy of Pediatrics. A monthly publication, it has been published continuously since 1948. PEDIATRICS is owned, published, and trademarked by the American Academy of Pediatrics, 141 Northwest Point Boulevard, Elk Grove Village, Illinois, 60007. Copyright () 2006 by the American Academy of Pediatrics. All rights reserved. Print ISSN: 0031-4005. Online ISSN: 1098-4275.

\section{American Academy of Pediatrics}




\title{
Psychiatric Morbidity in Children With Medically Unexplained Chronic Pain: Diagnosis From the Pediatrician's Perspective
}

\author{
Antoinette Y. Konijnenberg, MD, PhDa, Elisabeth R. de Graeff-Meeder, MD, PhD ${ }^{b}$, Joost van der Hoeven, MD ${ }^{b}$, Jan L. L. Kimpen, MD, PhDa, \\ Jan K. Buitelaar, MD, PhDc, Cuno S.P.M. Uiterwaal, MD, PhDd, the Pain of Unknown Origin in Children Study Group
}

Departments of aGeneral Pediatrics and bChild and Adolescent Psychiatry, Rudolf Magnus Institute of Neuroscience, University Medical Center Utrecht, Utrecht, Netherlands; ' Department of Psychiatry and Academic Center for Child and Adolescent Psychiatry, Nijmegen, Netherlands; ${ }^{\mathrm{d} D e p a r t m e n t ~ o f ~ C l i n i c a l ~ E p i d e m i o l o g y, ~ J u l i u s ~}$ Center for Health Sciences and Primary Care, Utrecht, Netherlands

The authors have indicated they have no financial relationships relevant to this article to disclose.

\section{ABSTRACT}

CONTEXT. There is very little general evidence to support the clinical management, particularly diagnosis, of medically unexplained chronic pain (UCP) in children.

OBJECTIVE. We sought to assess in children with UCP if clinical characteristics held important by general pediatricians help to accurately diagnose psychiatric morbidity and, alternatively, if the same can be achieved using dedicated questionnaires.

METHODS. We used a cross-sectional diagnostic study in a pediatric outpatient clinic of a university hospital. Our participants were 134 patients, aged 8 to 18 years, who were referred for UCP. Performed were (1) diagnostic test reflecting the pediatricians' choice of clinical characteristics and (2) selected questionnaires. Classification was performed according to the Diagnostic and Statistical Manual of Mental Disorders, Fourth Edition, by a child psychiatrist using the Diagnostic Interview Schedule for Children-Parent Version IV and the Semi-structured Clinical Interview for Children and Adolescents. Results were analyzed by logistic regression.

RESULTS. Psychiatric morbidity was present in 80 of the children. A minority had a medical explanation for the pain (15\% definite, $17 \%$ probable). The clinical diagnostic model included age, social-problem indicators, family structure, parental somatization, and school problems. In the quintile of children in whom this model predicted the highest risk, $93 \%$ indeed had psychiatric morbidity at reference testing. In the quintile with the lowest predicted risk, indeed only $27 \%$ had psychiatric morbidity. The Dutch Personality Inventory for Youth and the Child Behavior Checklist matched the pediatricians' choice of clinical characteristics. In the quintile of children with the highest predicted risk based on these questionnaires, $89 \%$ had psychiatric morbidity. In the quintile with the lowest predicted risk, only $15 \%$ had psychiatric morbidity.

CONCLUSIONS. A pediatrician-chosen set of clinical characteristics of children with UCP proves useful in diagnosing psychiatric morbidity. Using selected questionnaire screening yields similar results. www.pediatrics.org/cgi/doi/10.1542/ peds.2005-0109

doi:10.1542/peds.2005-0109

Key Words

chronic pain, psychiatry, predictive testing, diagnostic procedures, children, adolescents

Abbreviations

UCP — unexplained chronic pain PUC - Chronic Pain of Unknown Origin in Children

CHQ-CF_Child Health Questionnaire Child Form

CSI-Children's Somatization Inventory DPIY_Dutch Personality Inventory for Youth

CBCL_Child Behavior Checklist CFP_Checklist for Family Problems

DISC-P_Diagnostic Interview Schedule for Children-Parent Version IV

SCICA-Semi-structured Clinical Interview

for Children and Adolescents

DSM-IV - Diagnostic and Statistical Manual

of Mental Disorders, Fourth Edition

AUC - area under the curve

OR - odds ratio

df- degrees of freedom

$\mathrm{Cl}$ - confidence interval

Accepted for publication Jul 25, 2005

Address correspondence to Cuno S.P.M. Uiterwaal, MD, PhD, Department of Clinical Epidemiology, Julius Center for Health Sciences and Primary Care, D01.33.5, PO Box 85090, 3508 AB Utrecht, Netherlands. E-mail: c.s.p.m.uiterwaal@umcutrecht.nl

PEDIATRICS (ISSN Numbers: Print, 0031-4005; Online, 1098-4275). Copyright $\odot 2006$ by the American Academy of Pediatrics 
G ENERAL PEDIATRICIANS FREQUENTLY encounter children who are referred with medically unexplained chronic pain (UCP). If at initial evaluation no explanatory etiology can be identified, the chances of finding a clear somatic cause for the pain are known to be low. ${ }^{1-3}$ For medically UCP in children, a few studies from different settings have shown associations with psychosocial factors. ${ }^{4-6}$ There has been some research into indicators of psychiatric morbidity in children who are referred to pediatric primary care and in somatizing children. ${ }^{7-10}$ However, there is very little general evidence to support the clinical management of chronic pain in children in general, let alone specific evidence from diagnostic studies. ${ }^{11}$

Our Chronic Pain of Unknown Origin in Children (PUC) study is focused primarily on improving insight into the diagnostic process as a critical first step toward more evidence-based treatment of children with medically UCP. Clearly, an array of disorders may underlie medically UCP. A strictly dualistic approach toward somatic and psychiatric disorders is an underestimation of the complexity of the problem. However, for clinical purposes, it may prove useful to try to distinguish the extremes of the distribution of underlying disorders without any disregard for their interrelatedness. Given pediatricians' central role in the care for these children, they have to be able to detect both somatic and psychiatric disorders that accompany the pain as a prerequisite for proper diagnostic workup and subsequent treatment. ${ }^{8,9}$ Therefore, it is important that they have accurate and practical diagnostic tools at their disposal. However, various diagnostic routes may have substantially different implications for clinical practice. Therefore, we chose to evaluate 2 diagnostic approaches that may be considered mutual alternatives in practical care. In the first approach we aimed to evaluate the accuracy of pediatricians diagnosing psychiatric morbidity; in the second approach we aimed to evaluate the accuracy of using screening instruments that reflect pediatricians' ways of diagnosing psychiatric morbidity.

With regard to the pediatricians' diagnosis, one approach would be to scrutinize all regular intake information for diagnostic value, but this would involve an unmanageably large set of possible diagnostic markers. As a more logical and practical approach we questioned whether pediatricians' prior selections of clinical markers at intake that they deem relevant are sufficiently accurate to detect psychiatric disorders.

With regard to the screening approach, we questioned whether screening of all children with medically UCP using instruments that best reflect the pediatricians' selections is sufficiently accurate to detect psychiatric disorders.

\section{METHODS}

The PUC study was conducted in the Wilhelmina Children's Hospital, University Medical Center Utrecht, between January 2000 and July 2002. Children who presented to the outpatient clinic were eligible when they met the following criteria: age between 8 and 18 years; pain lasting for at least 3 months before the visit and without an explanatory diagnosis set by the referring doctor; first visit to a university pediatric outpatient clinic for this complaint; and sufficient knowledge of the Dutch language. Thus, a consecutive sample was assembled prospectively. Our clinic is organized such that $\sim 50 \%$ of the general pediatric outpatient population and $\sim 15 \%$ of the other pediatric departments consist of children who are evaluated only by a general practitioner before referral. Children were recruited mainly from the department of general pediatrics but also from the pediatric departments of neurology, orthopedics, immunology and rheumatology, gastroenterology, and urology. Every child was evaluated according to standard practice. After informed consent was given, additional research data were gathered through standardized interviews and a variety of questionnaires (see below). Reference testing for psychiatric morbidity was assessed through standardized psychiatric assessment. The institutional review board of our hospital approved the study.

\section{Diagnostic Index Tests: Identifying the General Pediatricians' Choices of Suspected Predictors of Psychiatric Morbidity}

From a database of the Pediatric Association of the Netherlands we invited 25 consecutive pediatricians to be members of a panel. Of these, 17 agreed and 8 refused for having a lack of time. The construction of a panel of pediatricians for the PUC study served 2 purposes. Because this procedure is relevant to the reproducibility of the study, a detailed description is provided here. First, panel members were asked to evaluate the medical charts and additional study measures of all children to define the optimal diagnostic approach and primary cause of the pain symptoms in each child. Results from this procedure are published elsewhere. ${ }^{12}$ Second, the 17 pediatricians were asked to fill out and return a mailed questionnaire that was aimed at identifying intake characteristics of patients with UCP that were deemed diagnostically important for psychiatric morbidity. The questionnaire was mailed, on average, 7 months (range: 6-9 months) after finishing the evaluation of the patient charts. One pediatrician did not return the questionnaire because of a traffic accident. Questionnaires were returned by 16 pediatricians, of whom 14 worked in regional pediatric hospitals, 1 in a rehabilitation center, and 1 in a university children's hospital. The questions that focused on possible predictors of psychiatry were phrased as follows: (1) What do you consider to be alarming symptoms for relevant psychological and/or 
psychiatric morbidity in a child presenting with UCP? (2) What do you consider to be alarming symptoms for relevant psychosocial or family problems in a child presenting with UCP? (3) What do you consider to be alarming symptoms for relevant somatic morbidity in a child presenting with UCP?

Subsequently, 3 researchers (A.Y.K., C.S.P.M.U., and E.R.d.G.-M.) independently screened the pediatricians' answers and identified 8 major domains of information that the pediatricians deemed relevant for diagnosing psychiatric morbidity (Table 1, column 1).

\section{Diagnostic Index Tests: Clinical Data}

A semistructured interview concerning medical and family history and a physical examination was performed by one of the researchers (A.Y.K.). The interview was held with the child and its parents(s) shortly after inclusion and before results of additional diagnostic investigations from routine care were known. This interview closely resembled routine medical history taking. Outcomes were coded into predefined categories. Clinical variables that matched the domains chosen by the pediatricians (Table 1, column 1) were translated into score variables for subsequent predictive analysis (Table 1, column 2).

For diagnostic modeling, the following basic characteristics were additionally scrutinized for diagnostic value: age, gender, and primary complaint.

\section{Diagnostic Index Tests: Screening Questionnaires}

Several questionnaires for the child and his or her parent(s) were filled out at home and returned before the results of additional diagnostic investigations from routine care were known and before the psychiatric assessment was conducted.

The Child Health Questionnaire Child Form (CHQ$\mathrm{CF}$ ) is a validated self-report health-status measure ${ }^{13}$ covering both physical and psychosocial domains. We used the scales on physical functioning, role/social limitations caused by physical problems, and general health perceptions. Scores range from 100 (no impairment) to 0 (severe impairment).

The Children's Somatization Inventory (CSI) is a reliable 35-item self-report inventory for somatic symptoms ${ }^{14}$ that measures the extent of bothering by a symptom in the past 2 weeks on a 5-point scale (0 ["not al all"] to 4 ["a whole lot"]). We considered a symptom to be present at a score of $\geq 1$.

The Dutch Personality Inventory for Youth (DPIY) is a 105-item validated self-report personality questionnaire. ${ }^{15}$ Total scores can be calculated for inadequacy, social inadequacy, tenacity, recalcitrance, and dominance. Statements are rated on a 3-point scale: 0 ("No, that is not me"), 1 ("I'm not sure"), and 2 ("Yes, that is me").

The Child Behavior Checklist (CBCL) is an extensively validated parent-report questionnaire that evalu-

TABLE 1 Operationalization of the Clinical Domains

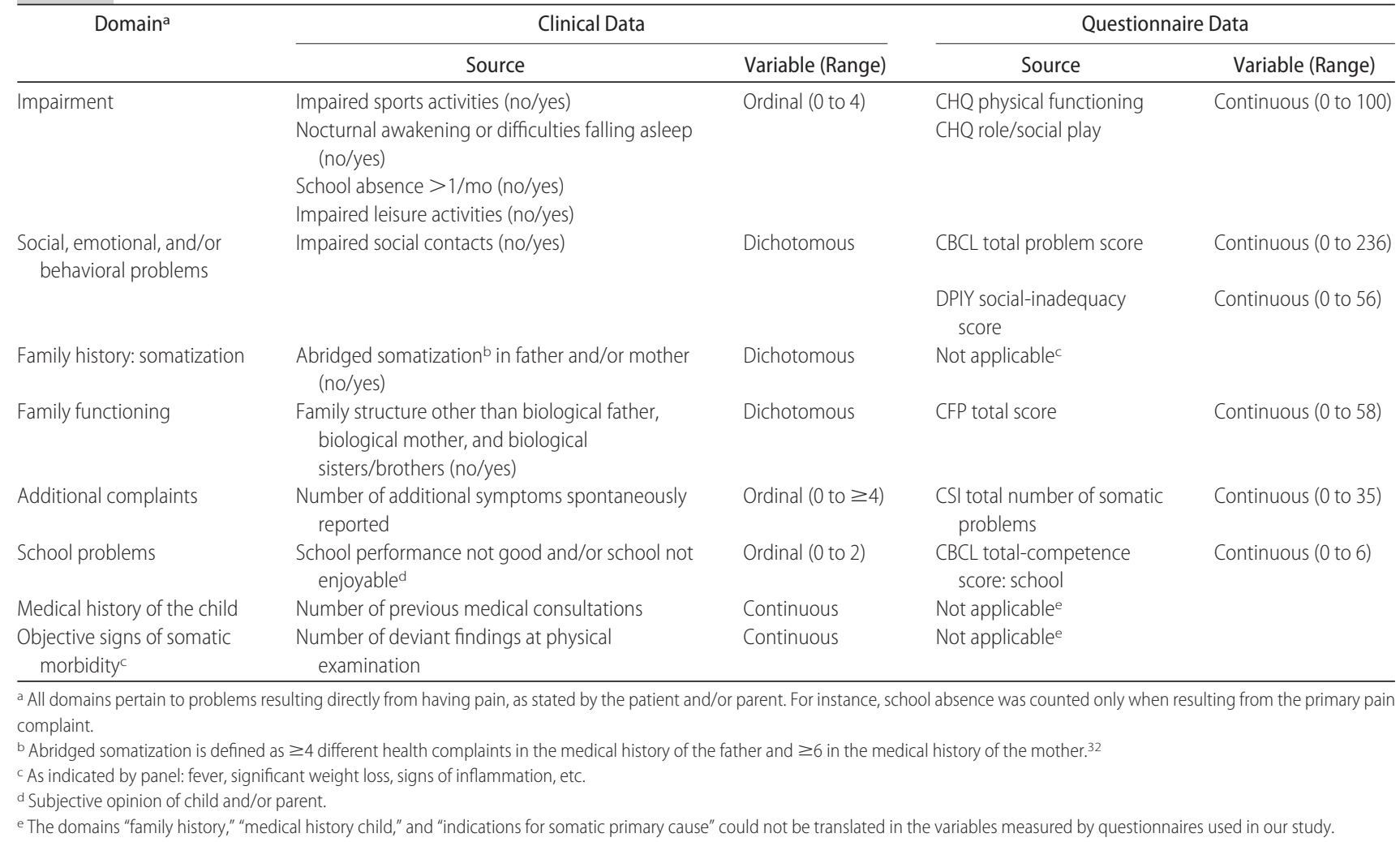


ates behavioral and emotional problems in children. ${ }^{16}$ It consists of competence (20 items) and problem (120 items) sections, each yielding total scores and normalized $T$ values for several domains. In this study, only the section's total scores were used.

The Checklist for Family Problems (CFP) is a Dutch family-problem inventory for which the theoretical frame was formed by the Family Assessment Measure. ${ }^{17}$ In our study, the screening part (29 items) of this questionnaire was used. Each question is rated from 0 ("not applicable to our situation") to 2 ("evidently/often applicable to our situation"). Total scores are calculated for men and women separately.

Questionnaire data were selected according to the domains identified by pediatricians (Table 1, column 3).

\section{Diagnostic Reference Test: Psychiatric Assessment}

The Diagnostic Interview Schedule for Children-Parent Version IV (DISC-P) is a highly structured respondentbased interview for children that was conducted by trained lay-interviewers. ${ }^{18}$ The Semi-structured Clinical Interview for Children and Adolescents (SCICA) mimics clinical interviewing by child psychiatrists in everyday clinical practice to assess a child's psychiatric functioning and Diagnostic and Statistical Manual of Mental Disorders (DSM) classification. ${ }^{19}$ An experienced child psychiatrist (J.v.d.H.), who received extensive training in using this method, conducted the interview.

Child and parent interviews were conducted simultaneously in separate rooms shortly after intake and before completion of the standard diagnostic workup. The child psychiatrist integrated the results from both the SCICA and the DISC-P into a final psychiatric classification according to DSM-IV diagnostic rules. If the DISC-P yielded a psychiatric outcome (ie, when DISC-P algorithm thresholds were reached), it was taken as a DSM-IV axis I diagnosis. In addition, the SCICA interview in itself could provide sufficient information to set a DSM-IV axis I diagnosis. Thus, a final psychiatric diagnosis was made by an experienced clinician based on child data, parent data, and/or a combination of both. Presence of the DSM-IV classification was used to classify children into the groups with psychiatric morbidity present and absent. The latter was used as the diagnostic reference test.

\section{Medical Diagnosis According to Routine Medical Care}

To assess the medical diagnosis from routine medical care, patient charts were analyzed 1 year after the first visit. A l-year time span was chosen to assure a full medical workup. The medical diagnosis was coded by the primary researcher (A.Y.K.) according to the system used by Reid et $a^{20,21}$ and Nimnuan et al. ${ }^{21}$ A second researcher (E.R.d.G.-M.) was consulted in case of uncertainty. Briefly, symptoms were coded as medically explained, probably medically unexplained, or definitely medically unexplained. Symptoms were considered medically unexplained when there was evidence of a comprehensive diagnostic workup, with the results of all investigations negative, and either psychosocial reasons were suggested or a diagnosis was made that implied a medically unexplained syndrome (eg, fibromyalgia, irritable bowel syndrome, chronic fatigue syndrome, etc). This method has shown good interrater reliability. ${ }^{20}$

\section{Data Analysis}

Univariate logistic regression was used to assess associations between each predictor variable and the reference test. Variables with $P$ values of $\leq .15$ were selected for additional analysis. Subsequently, multivariate logisticregression models were used to identify independent predictors by stepwise backward-selection methods (maximized likelihood; $P$ value for inclusion: .05; $P$ value for exclusion: .10), for the clinical data set and the screening data set separately. Thus, a final clinical and a final screening model were created. The model fit was estimated by using the Hosmer-Lemeshow test. ${ }^{22}$ For each of the final models, receiver operating characteristic curves were constructed, and the areas under the curves (AUCs) were estimated. The AUC represents the discriminative power of a test ranging from 0.5 (no discrimination) to 1.0 (perfect discrimination). ${ }^{23}$ As a means of internal validation (ie, to correct for overoptimism), a 100-sample bootstrapping procedure was performed on each model to calculate a shrinkage or correction factor to be applied to all regression coefficients. ${ }^{29}$ Thus, shrunken odds ratios (ORs) and AUCs were obtained.

Finally, a predicted probability for psychiatric morbidity was calculated for each patient by using the shrunken regression coefficients of each of the 2 models. As a check on the predictive capacity of the 2 models, a table was made to show risk categories predicted by the indextest model and the actually observed outcome of reference testing, analogous to the recommended flow diagram on diagnostic accuracy in the Standards for Reporting Diagnostic Accuracy (STARD) initiative. ${ }^{24}$ To prevent introducing bias and loss of statistical precision, we imputed missing values. Data were only imputed in case of $<10 \%$ missing values. Single regression imputation was used: a regression equation was fitted with use of all available variables to estimate as precisely as possible those values that were missing. ${ }^{25}$ Thus, per missing value an estimate was calculated on the basis of the other data available from that particular patient. For statistical analysis, the SPSS 11.5 (SPSS Inc, Chicago, IL) and S-plus 2000 (MathSoft, Seattle, WA) were used.

\section{RESULTS}

Figure 1 shows a flowchart of the inclusion procedure. Nonparticipants more often were boys (43\% vs $27 \%$; $\chi^{2}=4.5$, degrees of freedom $\left.[d f]=1 ; P=.04\right)$. The general characteristics (age, gender, pain type) and 
mean questionnaire scores $(\mathrm{CBCL}$, Dutch Personality Questionnaire for the Young, CSI, CHQ, CFP) of the 19 children who eventually were excluded were comparable to those of the children who were included.

Table 2 shows general patient characteristics, the final symptom classification according to routine medical care, and the outcome of the reference test (ie, the presence of psychiatric morbidity). In approximately one third of the children the final medical diagnosis, based on the patient chart from routine practice, was considered medically explained (15\% definite and $17 \%$ probable). Forty percent of these children also were diagnosed to have psychiatric morbidity, compared with $69 \%$ in those with medically unexplained symptoms $\left(\chi^{2}=8.2, d f=1 ; P=.007\right)$.

Table 3 shows general patient characteristics and the pediatrician-selected domains as univariate predictors of psychiatric morbidity. Age, the primary complaint, and 5 of the 8 selected domains were indeed associated with psychiatric morbidity. In addition, Table 3 shows that the domains, when matched to questionnaire data, also predicted the presence of psychiatric morbidity (except the CHQ).

Subsequent multivariate analysis of the clinical data yielded 5 predictors of psychiatric morbidity that were mutually independent (Table 4). Variables from the clinical model distinguished between psychiatric morbidity and nonpsychiatric morbidity (AUC: 79\% [95\% confidence interval (CI): $71-86 \%]$ ), which reduced to $72 \%$ after bootstrapping. The questionnaire model had a com-
TABLE 2 General Characteristics and Final Diagnosis of 134 Patients Referred With Medically UCP

\begin{tabular}{lc}
\hline Age, mean (SD), y & $11.8(2.6)$ \\
Girls, $n$ (\%) & $97(72)$ \\
Presenting symptom, $n$ (\%) & \\
Musculoskeletal pain & $40(30)$ \\
Abdominal pain & $31(23)$ \\
Headache & $59(44)$ \\
Other & $4(3)$ \\
Duration of pain, median (range), mo & $12(3-144)$ \\
Medical diagnosis from routine care, $n(\%)$ & \\
Medically unexplained & $91(68)$ \\
Probably medically unexplained & $23(17)$ \\
Medically explained & $20(15)$ \\
Referral status, $n$ (\%) & \\
Primary care & $47(35)$ \\
Secondary care & $87(65)$ \\
Psychiatric morbidity, $n$ (\%) & $80(60)$ \\
Nature of psychiatric morbidity, $n$ (\%) & \\
Anxiety disorder & $32(40)$ \\
Mood disorder & $28(35)$ \\
Disruptive disorder & $16(20)$ \\
Other disorder (adjustment disorder, & $4(5)$ \\
$\quad$ pervasive developmental disorder)
\end{tabular}

a If a child was only evaluated by a general practitioner prior to referral, a child was classified as referred from primary care. If, besides the general practitioner, a pediatrician or other consultant had evaluated the child, the child was classified as referred from secondary care.

parable discriminative power (AUC: $80 \%$ [95\% CI: $72-$ $88 \%]$ ), which reduced to $77 \%$ after bootstrapping.

Finally, we assessed whether the chance for psychiatric morbidity as predicted from the diagnostic models actually matched the findings at the diagnostic reference
FIGURE 1

Flowchart inclusion.

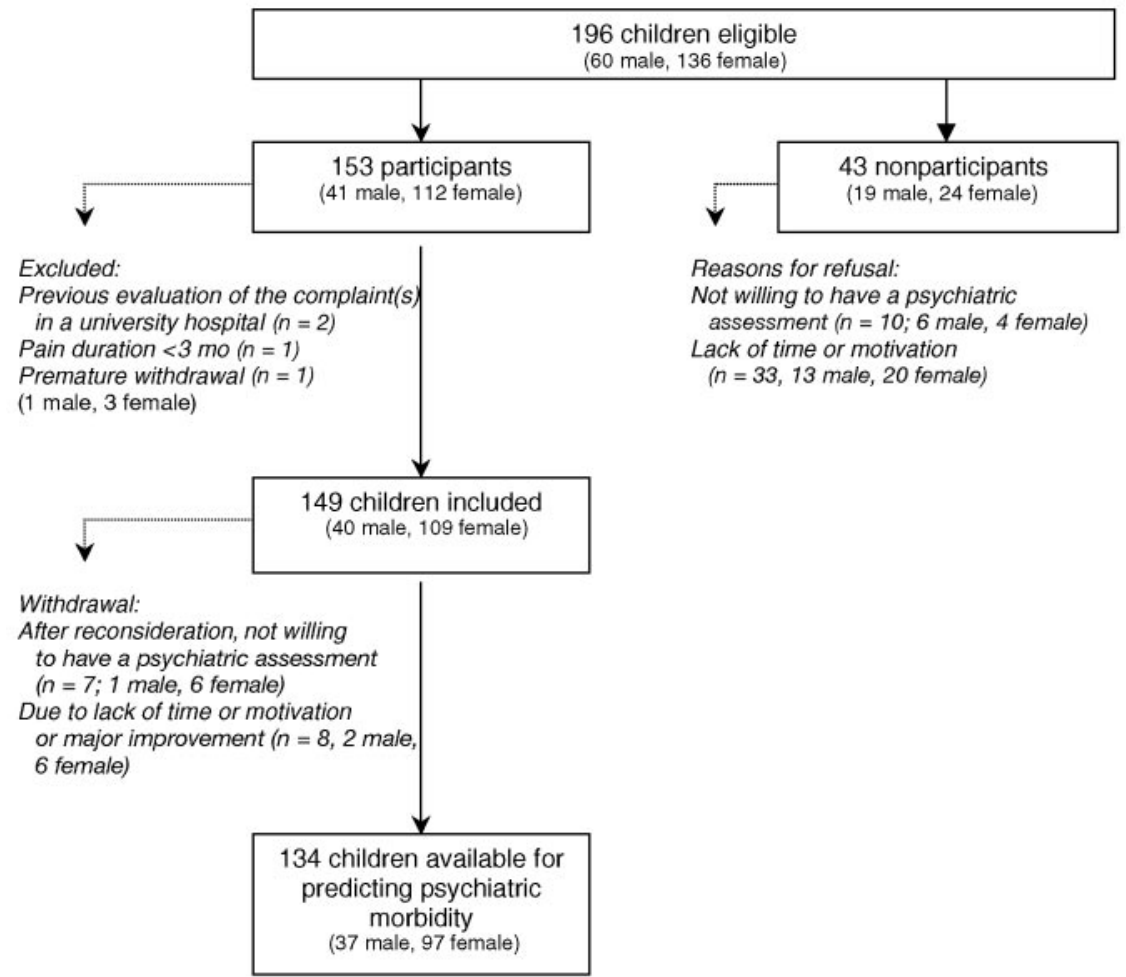


testing. Therefore, a predicted probability for psychiatric morbidity was calculated on the basis of each of the diagnostic models for each individual patient and tabulated by findings at reference testing of each patient. Table 5 shows a cross tabulation of the model-based estimated probabilities with the observed psychiatric classification from reference testing. A higher category (ie, a higher probability on psychiatry as predicted by each of the models) indeed was associated with a higher observed presence of psychiatric morbidity at reference testing. For instance, among the quintile $(n=27)$ patients who the clinical model predicted to be in riskcategory 5 for psychiatric morbidity, 25 (93\%) actually had psychiatric morbidity at reference testing (true-positives) compared with 24 (89\%) using the questionnaire model. Conversely, only 2 patients who were indicated as high risk by the model (category 5) did not show psychiatric morbidity at reference testing (false-positives). If the predicted risk was low (say, category 1 ), the clinical model missed 7 children $(27 \%)$ with actual psychiatric morbidity (false-negatives) compared with 4 children $(15 \%)$ using the questionnaire model.

\section{DISCUSSION}

Our results show that psychiatric morbidity can be predicted with considerable accuracy by using selected routine medical and family-history data. Alternatively, some screening questionnaires have similar diagnostic capacity.

Before discussing our results, some methodologic aspects of our study need to be addressed. Only a minor group stated psychiatric assessment as a reason for re-

TABLE 3 Univariate Associations Between Clinical and Questionnaire Data and Psychiatric Morbidity

\begin{tabular}{|c|c|c|}
\hline & OR $(95 \% \mathrm{Cl})$ & $P$ \\
\hline \multicolumn{3}{|l|}{ Clinical data } \\
\hline \multicolumn{3}{|l|}{ General patient characteristics } \\
\hline Age, y & $0.9(0.7-0.99)$ & .03 \\
\hline Gender (girl/boy) & $1.0(0.5-2.2)$ & 9 \\
\hline \multicolumn{3}{|l|}{ Primary complaint } \\
\hline Musculoskeletal pain & Reference & Reference \\
\hline Abdominal pain & $1.3(0.6-2.8)$ & .5 \\
\hline Headache & $3.2(1.2-8.5)$ & .02 \\
\hline \multicolumn{3}{|l|}{ Impairment } \\
\hline Impairments in daily life (range: $0-4$ ) & $1.03(0.8-1.4)$ & .8 \\
\hline \multicolumn{3}{|l|}{ Social, emotional, and/or behavioral problems } \\
\hline Impaired social contacts (no/yes) & $2.02(0.96-4.2)$ & .06 \\
\hline \multicolumn{3}{|l|}{ Family history } \\
\hline Abridged somatization in father and/or mother (no/yes) & $3.3(1.1-9.3)$ & .03 \\
\hline \multicolumn{3}{|l|}{ Family functioning } \\
\hline Nontypical family structure (no/yes) & $4.2(1.5-11.8)$ & .007 \\
\hline \multicolumn{3}{|l|}{ Symptom specific } \\
\hline No. of additional symptoms (range: $0-4$ ) & $1.4(1.03-1.9)$ & .03 \\
\hline \multicolumn{3}{|l|}{ School problems } \\
\hline None & Reference & Reference \\
\hline Bad performance or not enjoyable & $2.5(1.07-5.8)$ & .05 \\
\hline Bad performance and not enjoyable & $6.5(1.38-30.6)$ & .02 \\
\hline \multicolumn{3}{|l|}{ Medical history of child } \\
\hline No. of previous complaints (range: $0-10$ ) & $1.0(0.8-1.2)$ & .95 \\
\hline \multicolumn{3}{|l|}{ Indications for somatic primary cause } \\
\hline Objective symptoms on physical examination (range: $0-30$ ) & $0.9(0.9-1.0)$ & .2 \\
\hline \multicolumn{3}{|l|}{ Questionnaires } \\
\hline \multicolumn{3}{|l|}{ Impairment } \\
\hline CHQ role/social limitations (range: $0-100$ ) & $0.99(0.98-1.003)$ & .13 \\
\hline CHQ physical functioning (range: $0-100$ ) & $1.0(0.99-1.02)$ & 6 \\
\hline \multicolumn{3}{|l|}{ Social, emotional, and/or behavioral problems } \\
\hline CBCL total problem score (range: $0-236$ ) & $1.06(1.028-1.087)$ & $<.001$ \\
\hline DPIY social inadequacy (range: $0-56$ ) & $1.14(1.066-1.26)$ & $<.001$ \\
\hline \multicolumn{3}{|l|}{ Family functioning } \\
\hline CFP total score: mothers (range: $0-58, n=108)^{\mathrm{a}}$ & $1.06(0.99-1.11)$ & .06 \\
\hline \multicolumn{3}{|l|}{ Symptom specific } \\
\hline CSI total number of complaints (range: $0-35$ ) & $1.079(1.013-1.148)$ & .02 \\
\hline \multicolumn{3}{|l|}{ School problems } \\
\hline CBCL total competence: school (range: 0-6.0) & $0.57(0.395-0.84)$ & .003 \\
\hline
\end{tabular}


TABLE 4 Multivariate Predictors of Psychiatric Morbidity in a Clinical and a Questionnaire Prediction Model

\begin{tabular}{|c|c|c|}
\hline & OR $(95 \% \mathrm{Cl})$ & $\begin{array}{c}\text { Bootstrapped OR } \\
(95 \% \mathrm{Cl}) \\
\end{array}$ \\
\hline \multicolumn{3}{|l|}{ Clinical data ${ }^{a}$} \\
\hline \multicolumn{3}{|l|}{ General } \\
\hline Age, y & $0.79(0.67-0.94)$ & $0.85(0.72-1.01)$ \\
\hline \multicolumn{3}{|l|}{ Family functioning } \\
\hline Nontypical family structure (no/yes) & $6.07(1.92-19.19)$ & $3.42(1.08-10.81)$ \\
\hline \multicolumn{3}{|l|}{ Family history } \\
\hline Abridged somatization ${ }^{\mathrm{b}}$ in father and/or mother (no/yes) & $3.48(1.08-11.16)$ & $2.35(0.73-7.53)$ \\
\hline \multicolumn{3}{|l|}{ Social, emotional, and/or behavioral problems } \\
\hline Impaired social contacts (no/yes) & $2.41(1.00-5.77)$ & $1.82(0.76-4.36)$ \\
\hline \multicolumn{3}{|l|}{ School problems } \\
\hline None & Reference & Reference \\
\hline Bad performance or not enjoyable & $2.25(0.86-5.89)$ & $1.74(0.66-4.55)$ \\
\hline Bad performance and not enjoyable & $6.43(1.21-34.27)$ & $3.56(0.67-18.99)$ \\
\hline \multicolumn{3}{|l|}{ Questionnairesc } \\
\hline \multicolumn{3}{|l|}{ Social, emotional, and/or behavioral problems } \\
\hline CBCL total problem score (range: $2-81 ; n=130$ ) & $1.04(1.02-1.11)$ & $1.04(1.01-1.07)$ \\
\hline DPIY social inadequacy (range: $0-24 ; n=117$ ) & $1.13(1.04-1.24)$ & $1.10(1.03-1.19)$ \\
\hline \multicolumn{3}{|l|}{ School problems } \\
\hline CBCL total competence: school (range: 0-6.0) & $0.67(0.45-0.99)$ & $0.72(0.48-1.06)$ \\
\hline
\end{tabular}

TABLE 5 Predicted Probability Table for Each of the Models

\begin{tabular}{|c|c|c|c|c|c|c|}
\hline & \multicolumn{2}{|c|}{ Expected } & \multicolumn{4}{|c|}{ Observed } \\
\hline & \multirow[t]{2}{*}{ Total, $n(\%)$} & \multirow[t]{2}{*}{ Probability ${ }^{a}$} & \multicolumn{2}{|c|}{ Psychiatric Morbidity } & \multicolumn{2}{|c|}{ No Psychiatric Morbidity } \\
\hline & & & Patients, $n$ & $\%(95 \% \mathrm{Cl})$ & Patients, $n$ & $\%(95 \% \mathrm{Cl})$ \\
\hline \multicolumn{7}{|c|}{ Clinical model } \\
\hline \multicolumn{7}{|c|}{ Category } \\
\hline 1 & $26(20)$ & $0-0.44$ & 7 & $27(12-48)$ & 19 & $73(52-88)$ \\
\hline 2 & $27(20)$ & $0.45-0.53$ & 11 & $41(22-61)$ & 16 & $59(39-78)$ \\
\hline 3 & $27(20)$ & $0.54-0.65$ & 16 & $59(39-78)$ & 11 & $41(22-61)$ \\
\hline 4 & $27(20)$ & $0.66-0.77$ & 21 & $78(58-91)$ & 6 & $22(9-42)$ \\
\hline 5 & $27(20)$ & $0.78-1.0$ & 25 & $93(76-99)$ & 2 & $7(0-24)$ \\
\hline Total & & & 80 & $60(51-68)$ & 54 & $40(32-49)$ \\
\hline \multicolumn{7}{|c|}{ Questionnaire model } \\
\hline \multicolumn{7}{|c|}{ Category } \\
\hline 1 & $26(20)$ & $0-0.38$ & 4 & $15(0-35)$ & 22 & $85(65-96)$ \\
\hline 2 & $27(20)$ & $0.39-0.53$ & 13 & $48(29-68)$ & 14 & $52(32-71)$ \\
\hline 3 & $27(20)$ & $0.54-0.66$ & 19 & $70(50-86)$ & 8 & $30(14-50)$ \\
\hline 4 & $27(20)$ & $0.67-0.79$ & 20 & $74(54-89)$ & 7 & $26(11-46)$ \\
\hline 5 & $27(20)$ & $0.80-1.0$ & 24 & $89(71-98)$ & 3 & $11(0-29)$ \\
\hline Total & & & 80 & $60(51-68)$ & 54 & $40(32-49)$ \\
\hline
\end{tabular}

${ }^{a}$ Calculated probability for psychiatric morbidity using the clinical prediction model or the questionnaire prediction model.

fusal to participate. This group did not differ materially from other nonparticipants. Therefore, we do not think that nonresponse biased our results. Although we aimed to avoid too much deviation from routine practice, we added some semistructured interviewing to complete the clinical data. This may have rendered our intake data slightly more complete than one would find in regular practice. A stronghold of our study is that we used extensive gold-standard reference testing for psychiatric morbidity in all children who participated.
Ideally, pediatricians involved in the care of children with UCP have proper tools for early recognition of both somatic and psychiatric disorders that underlie the complaints. In regular practice, pediatricians do cope with the problem, but there is very little formal evidence to support their actions. We verified whether clinical patient characteristics deemed important by pediatricians do actually predict the presence or absence of psychiatric disorder in children with UCP. In previous reports, a number of patient characteristics such as parental illness, 
educational problems, an increased number of health concerns, and problematic social competence were shown to be associated with specific somatization in children. ${ }^{10,26}$ Although UCP is not synonymous to somatization, a similar set of characteristics was predictive in our study for the diagnosis of psychiatric disorders.

All clinical predictors were associated with psychiatric disorder in the expected direction, except perhaps for age. Age was an important independent predictor, but the younger the child was, the higher the chances of finding psychiatric morbidity were. One explanation might be the tendency for younger children to present psychiatric morbidity with a predominantly somatic vocabulary, contrary to older children. ${ }^{27}$ An explanation that we cannot formally exclude is that adolescents with UCP had dissimulated psychiatric symptoms at reference testing. However, because an experienced child psychiatrist performed this testing by using various sources, we consider the latter to be an unlikely explanation. As expected, abridged parental somatization, impaired social contacts, problems at school, and nontypical family structure were each positive predictors of psychiatric disorders in the children.

We know of no formal guidelines or protocols for diagnosis or treatment in children with UCP, indicating that care is at least not highly structured. Furthermore, there may be large differences in the organization of care for children with UCP. Therefore, we also explored the possibility of questionnaire screening for psychiatric problems as a diagnostic option. The combined information of the CBCL and the Dutch Personality Questionnaire for the Young was similarly accurate as routine history taking in diagnosing psychiatric morbidity among children with UCP.

We consider our diagnostic evidence important for a number of reasons. Our gold-standard test, elaborate psychiatric assessment, is not available in every pediatric facility, nor is such assessment of every child with UCP desirable or feasible. It is important to note that early detection of psychiatric morbidity by simple and available methods will be much to a child's benefit, because it facilitates timely, appropriate, and targeted action in that direction. ${ }^{8}$ It is clear that labeling of the complaints in a direction of "medically unexplained" or "psychological or psychiatric" may hamper relations between physicians and patients. ${ }^{28}$ However, at the same time, is has to be acknowledged that psychiatric morbidity is highly prevalent in children with UCP. Unfortunately, there still is insufficient understanding of the relation between psychiatric disorders and medically unexplained complaints, particularly in children.

To our knowledge, our study is the first formal diagnostic approach to the problem of children with UCP. This implies some caution toward implementation of the results. We obtained our prediction models from our derivation set only. Although we did use bootstrapping techniques as an accepted means of internal validation, clinical application will require additional external validation. ${ }^{29,30}$ However, we feel that our results are sufficiently promising to warrant additional research in this area.

Distinct markers for somatic pathology were not identified in our sample. In itself this is not surprising, given the fact that children were referred by pediatricians or general practitioners who were not able to fully explain the symptoms. However, proper pediatric assessment, of course, is still mandatory in a child who presents with UCP. Although the proportion is small, some children do have a (comorbid) somatic explanation for their pain. We do feel that more attention to psychiatry as a putative explanation of UCP should be given, but this should not lead to a relative neglect for somatic assessment. ${ }^{31}$

\section{CONCLUSIONS}

We find that pediatricians are sufficiently aware of signals to detect early psychiatric morbidity in children with UCP. More formal questionnaires may be an important diagnostic backup.

\section{ACKNOWLEDGMENTS}

All residents and consulting physicians of the Wilhelmina Children's Hospital are gratefully acknowledged for assistance with patient recruitment.

The members of the Pain of Unknown Origin in Children (PUC) Study Group members are (in alphabetical order): Pieter J. van Dijken, MD, PhD, MBA, St Elisabeth Hospital, Tilburg, Netherlands; Regina H.M. DijkmanNeerincx, MD, Rijnstate Hospital, Arnhem, Netherlands; Alphons H.P.M. Essink, MD, Hieronymus Bosch Hospital, 's-Hertogenbosch, Netherlands; Boudien C.T. Flapper, MD, Beatrixoord, Haren, Netherlands; Ellen A. Fliers, MD, Department for Youth, RIAGG Rijnmond Zuid, Rotterdam, Netherlands; Jeanette K. ten Haaf, MD, MESOS Medical Center, Utrecht, Netherlands; Marchinus Hofkamp, MD, Gelre Hospitals, Apeldoorn, Netherlands; Syb B. van der Meer, MD, PhD, Atrium Medical Center, Heerlen, Netherlands; Marijn Moens, MD, Hospital Diakonessenhuis, Zeist, Netherlands; Rolf A.A. Pelleboer, MD, Catharina Hospital, Eindhoven, Netherlands; Aart van Rhijn, MD, Hospital Eemland, Amersfoort, Netherlands; Ingrid M.B. Russel, MD, University Medical Center Utrecht, Utrecht, Netherlands; Bernadien T.M.J. Thunnissen, MD, Center for Astma Heideheuvel, Hilversum, Netherlands; Arine M. Vlieger, MD, Antonius Hospital, Nieuwegein, Netherlands; Johanna M.B. Wennink, MD, PhD, St Lucas Andreas Hospital, Amsterdam, Netherlands; Hester van Wieringen, MD, MESOS Medical Center, Utrecht, Netherlands; and Pieter Zwart, MD, Isala Clinics, de Weezenlanden, Zwolle, Netherlands 


\section{REFERENCES}

1. Deda G, Caksen H, Ocal A. Headache etiology in children: a retrospective study of 125 cases. Pediatr Int. 2000;42:668-673

2. Croffie JM, Fitzgerald JF, Chong SK. Recurrent abdominal pain in children: a retrospective study of outcome in a group referred to a pediatric gastroenterology practice. Clin Pediatr (Phila). 2000;39:267-274

3. Malleson PN, Connell H, Bennett SM, Eccleston C. Chronic musculoskeletal and other idiopathic pain syndromes. Arch Dis Child. 2001;84:189-192

4. Apley J. The child with recurrent abdominal pain. Pediatr Clin North Am. 1967;14:63-72

5. Campo JV, Comer DM, Jansen-McWilliams L, Gardner W, Kelleher KJ. Recurrent pain, emotional distress, and health service use in childhood. J Pediatr. 2002;141:76-83

6. Merlijn VP, Hunfeld JA, van der Wouden JC, HazebroekKampschreur AA, Koes BW, Passchier J. Psychosocial factors associated with chronic pain in adolescents. Pain. 2003;101: 33-43

7. Reinherz HZ, Paradis AD, Giaconia RM, Stashwick CK, Fitzmaurice G. Childhood and adolescent predictors of major depression in the transition to adulthood. Am J Psychiatry. 2003; 160:2141-2147

8. Briggs-Gowan MJ, Horwitz SM, Schwab-Stone ME, Leventhal JM, Leaf PJ. Mental health in pediatric settings: distribution of disorders and factors related to service use. $J$ Am Acad Child Adolesc Psychiatry. 2000;39:841-849

9. Costello EJ, Costello AJ, Edelbrock C, et al. Psychiatric disorders in pediatric primary care: prevalence and risk factors. Arch Gen Psychiatry. 1988;45:1107-1116

10. Garralda ME. Somatisation in children. J Child Psychol Psychiatry. 1996;37:13-33

11. Eccleston C, Malleson P. Managing chronic pain in children and adolescents: we need to address the embarrassing lack of data for this common problem. BMJ. 2003;326:1408-1409

12. Konijnenberg AY, Graeff-Meeder ER, Kimpen JL, van der HJ, Buitelaar JK, Uiterwaal CS. Children with unexplained chronic pain: do pediatricians agree regarding the diagnostic approach and presumed primary cause? Pediatrics. 2004;114:1220-1226

13. Landgraf JM, Abetz L, Ware JE. The CHQ User's Manual. Boston: MA: The Health Institute, New England Medical Center; 1996

14. Meesters C, Muris P, Ghys A, Reumerman T, Rooijmans M. The Children's Somatization Inventory: further evidence for its reliability and validity in a pediatric and a community sample of Dutch children and adolescents. J Pediatr Psychol. 2003;28: 413-422

15. Luteijn F, Starren J, van Dijk H. Handleiding bij de Nederlandse persoonlijkheidsvragenlijst. Lisse, Netherlands: Swets $\delta$ Zeilinger; 1985

16. Hofstra MB, Van der EJ, Verhulst FC. Child and adolescent problems predict DSM-IV disorders in adulthood: a 14-year follow-up of a Dutch epidemiological sample. J Am Acad Child Adolesc Psychiatry. 2002;41:182-189

17. Koot HM. Manual for the Dutch Questionnaire for Family Problems [in Dutch]. Rotterdam, Netherlands: Sophia Children's Hospital, Erasmus University; 1997

18. Shaffer D, Fisher P, Lucas CP, Dulcan MK, Schwab-Stone ME. NIMH Diagnostic Interview Schedule for Children Version IV (NIMH DISC-IV): description, differences from previous versions, and reliability of some common diagnoses. J Am Acad Child Adolesc Psychiatry. 2000;39:28-38

19. Ferdinand RF, Hoogerheide KN, Van der EJ, et al. The role of the clinician: three-year predictive value of parents-teachers' and clinicians' judgment of childhood psychopathology. J Child Psychol Psychiatry. 2003:44:867-876

20. Reid S, Crayford T, Richards S, Nimnuan C, Hotopf M. Recognition of medically unexplained symptoms: do doctors agree? J Psychosom Res. 1999;47:483-485

21. Nimnuan C, Hotopf M, Wessely S. Medically unexplained symptoms: how often and why are they missed? QJM. 2000; 93:21-28

22. Hosmer DW, Hosmer T, Le Cessie S, Lemeshow S. A comparison of goodness-of-fit tests for the logistic regression model. Stat Med. 1997; 16:965-980

23. Hanley JA, McNeil BJ. The meaning and use of the area under a receiver operating characteristic (ROC) curve. Radiology. 1982;143:29-36

24. Bossuyt PM, Reitsma JB, Bruns DE, et al. Towards complete and accurate reporting of studies of diagnostic accuracy: the STARD initiative. Standards for Reporting of Diagnostic Accuracy. Clin Chem. 2003;49:1-6

25. Engels JM, Diehr P. Imputation of missing longitudinal data: a comparison of methods. J Clin Epidemiol. 2003;56:968-976

26. Campo JV, Fritsch SL. Somatization in children and adolescents. J Am Acad Child Adolesc Psychiatry. 1994;33:1223-1235

27. Rutter M, Taylor E. Child and Adolescent Psychiatry. Oxford, United Kingdom: Blackwell; 2002

28. Stone J, Wojcik W, Durrance D, et al. What should we say to patients with symptoms unexplained by disease? The "number needed to offend." BMJ. 2002;325:1449-1450

29. Steyerberg EW, Harrell FE Jr, Borsboom GJ, Eijkemans MJ, Vergouwe Y, Habbema JD. Internal validation of predictive models: efficiency of some procedures for logistic regression analysis. J Clin Epidemiol. 2001;54:774-781

30. Bleeker SE, Moll HA, Steyerberg EW, et al. External validation is necessary in prediction research: a clinical example. $J$ Clin Epidemiol. 2003;56:826-832

31. Wessely S, Nimnuan C, Sharpe M. Functional somatic syndromes: one or many? Lancet. 1999;354:936-939

32. Escobar JI, Gara M, Silver RC, Waitzkin H, Holman A, Compton W. Somatisation disorder in primary care. Br J Psychiatry. $1998 ; 173: 262-266$ 


\section{Psychiatric Morbidity in Children With Medically Unexplained Chronic Pain: Diagnosis From the Pediatrician's Perspective}

Antoinette Y. Konijnenberg, Elisabeth R. de Graeff-Meeder, Joost van der Hoeven, Jan L. L. Kimpen, Jan K. Buitelaar and Cuno S.P.M. Uiterwaal

Pediatrics 2006;117:889

DOI: $10.1542 /$ peds. 2005-0109

\section{Updated Information \& Services}

References

Citations

Subspecialty Collections

Permissions \& Licensing

Reprints including high resolution figures, can be found at: http://pediatrics.aappublications.org/content/117/3/889.full.ht $\mathrm{ml}$

This article cites 28 articles, 9 of which can be accessed free at:

http://pediatrics.aappublications.org/content/117/3/889.full.ht ml\#ref-list-1

This article has been cited by 6 HighWire-hosted articles: http://pediatrics.aappublications.org/content/117/3/889.full.ht ml\#related-urls

This article, along with others on similar topics, appears in the following collection(s):

Neurology \& Psychiatry

http://pediatrics.aappublications.org/cgi/collection/neurology _and_psychiatry

Information about reproducing this article in parts (figures, tables) or in its entirety can be found online at:

http://pediatrics.aappublications.org/site/misc/Permissions.xht $\mathrm{ml}$

Information about ordering reprints can be found online: http://pediatrics.aappublications.org/site/misc/reprints.xhtml

PEDIATRICS is the official journal of the American Academy of Pediatrics. A monthly publication, it has been published continuously since 1948. PEDIATRICS is owned, published, and trademarked by the American Academy of Pediatrics, 141 Northwest Point Boulevard, Elk Grove Village, Illinois, 60007. Copyright @ 2006 by the American Academy of Pediatrics. All rights reserved. Print ISSN: 0031-4005. Online ISSN: 1098-4275.

\section{American Academy of Pediatrics}

DEDICATED TO THE HEALTH OF ALL CHILDREN ${ }^{\mathrm{m}}$ 